\title{
reviews
}

\section{Functional biology of the mollusca}

R. D. Purchon

Living Marine Molluscs. By C. M. Yonge and T. E. Thompson. Pp. 288. (Collins: London, 1976.) $£ 6.00$.

BeAutifully illustrated with sixteen $\circ$ plates (eight in colour) and with 162 informative line diagrams, this inexpensive book fills a major gap in libraries. It will be invaluable to university students; malacologists and palaeontologists professionally concerned with understanding functional morphology and the principles of molluscan evolution; conchologists; and enthusiastic amateur shell collectors.

The text, arranged in eighteen chapters all of a convenient size, is an easily understood narrative reviewing the functional biology and evolution of all the more important molluscan taxa, on a global scale. There is also a wealth of minor detail regarding the species of British marine mollusca.

After a brief introduction, chapter 1 is devoted to an historical review of molluscan studies to the present day. It remains for the reviewer to emphasise that the past half century has seen an explosive growth in the study of the functional biology of molluscs, to which no-one has contributed as extensively as has the senior author of this book.

Chapters 2, 3 and 4 deal with basic features of molluscan organisation and classification, and with the chitons which, with their eight overlapping shell plates and muscular foot, are adapted for movement over irregular hard surfaces. Chapters 5-9 concern the Prosobranchia, dealing successively with "The first gastropods": "Limpets and top shells"; "Mesogastropods" (which require two chapters); and with "Neogastropods". Here is a wealth of well-explained functional biology and ecological detail. These chapters portray the evolutionary plasticity of the Prosobranchia. and the resourcefulness of the Mesogastropoda in particular.

The next two chapters concern "Opisthobranch sea snails", and "Sea slugs". Reduction of the shell here leads to alternative chemical and biological protection against predators. After lightening, or loss, of the shell several lineages have independently acquired the ability to swim, the better to escape from their enemies. We can appreciate something of the grace and

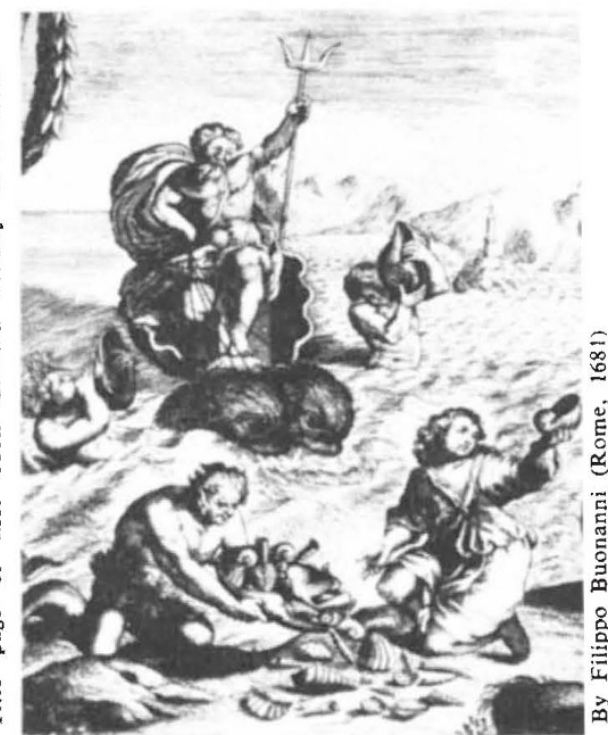

heauty of these delightful animals from the excellent line and stipple drawings here.

Five and a half chapters are assigned to the Bivalvia, beginning with an account of the origin of primitive bivalves from a generalised molluscan ancestry, and covering the general organisation and mode of growth of bivalves. In "Evolution and adaptation of bivalves" we see a transition from deposit-feeding protobranchs to suspension-feeding lamellibranchs, with elaboration of ctenidial ciliary sorting mechanisms. These lamellibranchs exploit every possible aquatic habitat and mode of life, as is shown in chapters 14-16: byssal attachment to hard surfaces, with the adoption of heteromyarian or monomyarian form: swimming; shallow or deep burrowing in sediment, with a return to deposit feeding in the Tellinacea; commensalism; and boring in rock and timber by pholads and shipworms.

Chapter 17, "Anomalous bivalves and scaphopods", deals first with the Anomalodesmata, which lack hinge teeth and in some of which there is a lithodesma. The Verticordiidae indicate a transition from filter feeding to a scavenging or carnivorous habit, as also in the related Septibranchia. This was a necessary pre-adaptation towards life in abyssal sediments. Mention is made of the Watering Can Shell, Penicillus, which calls for a special effort by functional morphologists, who happen to be well-placed in the Indo-Pacific Region, to elucidate the general biology and growth processes of early stages of this puzzling bivalve.

The Scaphopoda are shown to be either microphagous (Dentalium conspicuum), or carnivorous (D. entalis).

Chapter 18, "Cuttlefish, squid and octopus", relates the mantle cavity of these actively swimming molluscs to those of other molluscan classes. Attention is given to newly gained knowledge of the biology of the Pearly Nautilus, which moves slowly in moderately deep waters. Transition from ciliary to muscular ventilation of the mantle cavity permitted fast swimming, and required a high metabolic rate. This permitted the exploitation by cephalopods of waters from just above the seabed to the surface of the sea. In such pelagic hunters the statocysts, eyes, and brain are well developed, as also the tactile sense in octopods, which have secondarily returned to the seabed. A brief account is given of learning and memory in the octopus, and how knowledge of this has been gained by simple experiments.

The substance of the book is surveyed in an Epilogue. The mollusca arose with the contrasted advantages accruing from a bilaterally symmetrical body and a radially symmetrical protective shell; these, with the versatile radular apparatus, provided a basis for diversification to suit widely different habitats and modes of life. By acquisition of neutral buoyancy and muscular jet propulsion the cephalopoda outstripped all other invertebrates and now compete on equal terms with the marine (but not freshwater) Teleostei.

Erato voluta (Fig. 34, p86), until recently regarded as a cypraeid, should be assigned to the family Eratoidae totogether with the genus Trivia. $X$ ylophaga (p218) is reported as being unable to swallow fragments of the wood through which it bores, but this is not so; it has a moderately large caecum which is normally packed with wood fragments.

There is a useful list of recommended books for further reading, and there is a thorough index. Typographical errors are rare.

R. D. Purchon is Professor of Zoology at Chelsea College, University of London, UK. 